\title{
BMJ Open What are the cost-savings and health benefits of improving detection and management for six high cardiovascular risk conditions in England? An economic evaluation
}

\author{
Chloe Thomas (D) , ${ }^{1}$ Alan Brennan, ${ }^{1}$ Edward Goka, ${ }^{1}$ Hazel Y Squires, ${ }^{1}$ \\ Gilly Brenner, ${ }^{2}$ David Bagguley, ${ }^{1}$ Helen Buckley Woods, ${ }^{1}$ Michael Gillett, ${ }^{1}$ \\ Joanna Leaviss, ${ }^{1}$ Mark Clowes, ${ }^{1}$ Laura Heathcote,${ }^{1}$ Katy Cooper, ${ }^{1}$ Penny Breeze ${ }^{1}$
}

To cite: Thomas C, Brennan A, Goka $\mathrm{E}$, et al. What are the cost-savings and health benefits of improving detection and management for six high cardiovascular risk conditions in England? An economic evaluation. BMJ Open 2020;10:e037486. doi:10.1136/ bmjopen-2020-037486

- Prepublication history and additional material for this paper are available online. To view these files, please visit the journal online (http://dx.doi. org/10.1136/bmjopen-2020037486).

Received 04 February 2020 Revised 09 June 2020 Accepted 19 June 2020

Check for updates

(c) Author(s) (or their employer(s)) 2020. Re-use permitted under CC BY-NC. No commercial re-use. See rights and permissions. Published by BMJ.

${ }^{1}$ School of Health \& Related Research, University of Sheffield, Sheffield, UK

${ }^{2}$ Rotherham Metropolitan Borough Council, Rotherham, UK

Correspondence to

Dr Chloe Thomas;

c.thomas@sheffield.ac.uk

\section{ABSTRACT}

Objectives To estimate the cost savings and health benefits of improving detection of individuals at high risk of cardiovascular disease (CVD) in England, to determine to which patient subgroups these benefits arise, and to compare different strategies for subsequent management. Design An economic analysis using the School for Public Health Research CVD Prevention Model.

Setting England 2018.

Participants Adults aged 16 and older with one or more high cardiovascular risk conditions, including hypertension, diabetes, non-diabetic hyperglycaemia, atrial fibrillation, chronic kidney disease and high cholesterol.

Interventions Detection of $100 \%$ of individuals with CVD high risk conditions compared with current levels of detection in England. Detected individuals are assumed to be managed either according to current levels of care or National Institute of Health and Care Excellence (NICE) guidelines.

Main outcome measures Incremental and cumulative costs, savings, quality adjusted life years (QALYS), CVD cases, and net monetary benefit, from a UK NHS and Personal Social Services perspective.

Results £68 billion could be saved, 4.9 million QALYs gained and 3.4 million cases of CVD prevented over 25 years if all individuals in England with the six CVD high risk conditions were diagnosed and subsequently managed at current levels. Additionally, if all detected individuals were managed according to NICE guidelines, total savings would be $£ 61$ billion, 8.1 million QALYs would be gained and 5.2 million CVD cases prevented. Most benefits come from detection of high cholesterol in the short term and diabetes in the long term.

Conclusions Substantial cost savings and health benefits would accrue if all individuals with conditions that increase CVD risk could be diagnosed, with detection of undiagnosed diabetes producing greatest benefits. Ensuring all conditions are managed according to NICE guidelines would further increase health benefits. Projected cost-savings could be invested in developing acceptable and cost-effective solutions for improving detection and management.

\section{Strengths and limitations of this study}

- Based on a single modelling framework that includes most elements of current cardiovascular disease (CVD) prevention practice in people at high risk in England, and thereby enables valid comparison of different detection and management scenarios.

- The patient-level model structure preserves correlations between high risk conditions, meaning that the combined benefits of detecting multiple high risk conditions can be assessed without either double counting or underestimating CVD risk in people with multiple comorbidities.

- Results depend on accurate modelling of current care in England; however, this depends on a range of data sources that vary between highly accurate Quality and Outcomes Framework data and published observational studies based on a limited sample.

- The CVD prevention benefits of improving detection and management could be underestimated because the model does not include some vascular conditions such as peripheral vascular disease, does not include CVD benefits of lifestyle management interventions that go beyond the recorded effect on metabolic factors, and does not model secondary CVD events in a way that enables interventions to directly impact them.

\section{INTRODUCTION}

Cardiovascular disease (CVD) prevention is a major global public health priority, despite recent reductions in mortality. ${ }^{2}$ Currently there are over 1.8 million people in England on the Coronary Heart Disease Register and over 1 million on the Stroke or Transient Ischaemic Attacks Register, ${ }^{2}$ with CVD estimated to cost the UK economy $€ 26$ billion overall in 2015. ${ }^{1}$ As part of its strategy to improve CVD prevention, NHS RightCare 
has highlighted six high risk conditions for CVD that are currently under-diagnosed and insufficiently well managed despite a range of available interventions. ${ }^{3}$ These conditions include hypertension, atrial fibrillation (AF), high cholesterol/high CVD risk comprising those with a QRISK score of at least $10 \%$ and those with familial hypercholesterolaemia $(\mathrm{FH})$, diabetes (type 1 and type 2), non-diabetic hyperglycaemia (NDH; HbA1c $42-48 \mathrm{mmol} / \mathrm{mol}$ ), and chronic kidney disease (CKD). Many CVD events are preventable through pharmacological interventions and lifestyle changes. Clinical guidelines in Europe and several other countries support population wide programmes to assess and manage cardiovascular risk in individuals. ${ }^{4}$ Examples of national CVD risk assessment and management programmes include the NHS Health Check programme in England, ${ }^{5}$ Keep Well in Scotland ${ }^{6}$ and More Heart and Diabetes Checks in New Zealand. ${ }^{7}$ Nevertheless, in England detection rates for cardiovascular risk remain low and significant opportunities remain to reduce risks through treatment and lifestyle changes. ${ }^{89}$

While it appears evident that increasing diagnosis and management of these six conditions could be an achievable way of making health improvements and potentially saving costs to the NHS, little quantification of the potential benefits has been carried out. While evaluations of the NHS Health Checks have considered the benefits of increased uptake of statins, antihypertensive treatment and lifestyle modification, detection and management of diabetes, $\mathrm{NDH}, \mathrm{CKD}$, and $\mathrm{AF}$ were not within the scope of these previous analyses. ${ }^{10-12}$ In 2017, Public Health England (PHE) produced the Size of the Prize in CVD prevention, ${ }^{13}$ an analysis which estimates the potential benefits of increasing treatment for hypertension and $\mathrm{AF}$, but does not consider the impact of improving detection, nor include the other high risk conditions. Modelling of the entire diagnostic and treatment pathway has been carried out for some conditions including $\mathrm{AF}^{14}$ while other evaluations have considered particular CVD prevention strategies (eg, statins ${ }^{15}$ ). However, no previous analysis has considered all six high risk conditions and their currently used interventions within a single framework that enables valid comparison between different detection and management guidelines.

The aim of this analysis was to estimate the total cost savings and health benefits that could be produced if it were possible to detect all individuals with the six high risk conditions in England, assuming that diagnosed individuals would be either managed to current care levels, or optimally according to National Institute for Health and Care Excellence (NICE) guidelines. In addition, the analysis explored which high risk groups benefit the most from optimal detection in terms of cost savings and health benefits. This analysis takes an NHS and Personal Social Services perspective.

\section{METHODS}

\section{Model background}

The analysis was carried out using the School for Public Health Research (SPHR) CVD Prevention Model, developed as an adaptation of the SPHR Diabetes Prevention Model, which has been previously used to evaluate a range of diabetes prevention strategies, including the NHS Diabetes Prevention Programme (NHS DPP). ${ }^{16-18}$ Online supplementary file 1 includes full details of the model background and adaptations. In brief, the model is an individual patient microsimulation model written in $\mathrm{R}$, with annual cycles and a lifetime horizon, based on correlated personalised trajectories of metabolic risk factors (body mass index, blood pressure, cholesterol and HbA1c). The model setting is the English NHS and social services. Baseline patient characteristics are taken from the Health Survey for England (HSE) $2014^{19}$ to enable a patient population representative of England to be modelled.

\section{Model development and assumptions}

In any year of the model, individuals may develop one or more of the included six high risk conditions (hypertension, high cholesterol (defined as QRISK2 score for CVD risk $\geq 10 \%$ or $\mathrm{FH}$ ), type 1 and 2 diabetes, $\mathrm{NDH}, \mathrm{AF}$ and $\mathrm{CKD}$ ), and undergo diagnosis and management with one or more CVD prevention interventions, according to eligibility criteria. Interventions for inclusion in the model were selected from the NICE guidance for each of the high risk conditions. ${ }^{20-27}$ These include diagnostic interventions (NHS Health Check, annual review for people with a pre-existing high risk condition, cascade testing for FH and opportunistic diagnosis), pharmacological interventions (lipid modification, antihypertensives, anticoagulants and diabetes treatments), lifestyle interventions (weight management, smoking cessation, structured education for diabetes, NHS DPP and nutritional advice for CKD) and interventions to improve adherence to other interventions (blood pressure selfmonitoring, medicines use review and insulin pump for type one diabetes). A series of rapid reviews were carried out to identify the best quality evidence around effectiveness and costs for each intervention. A small number of NICE recommended interventions were not included due to insufficient data quality (alcohol brief interventions, exercise referral and brief diet and lifestyle advice). Full details of the search strategies, reviewing methodology and results can be found in online supplementary file 1. Decisions about which evidence and assumptions to include in the model (eg, around duration of effect for each intervention, or eligibility criteria) were taken in conjunction with clinical experts.

Primary CVD events are modelled using a combination of QRISK2 and QStroke algorithms to assign separate annual cardiac and stroke risks, ${ }^{28}{ }^{29}$ with event rates determined stochastically. QRISK2 includes myocardial infarction (MI), angina, stroke and transient ischaemic attack (TIA). Congestive heart failure is modelled separately 
using Framingham risk equations. ${ }^{30}$ Other CVD conditions (eg, peripheral vascular disease) are not modelled. Modifications were made to the QRISK and QStroke algorithms to enable the CVD impact of all high risk conditions and interventions to be included. QRISK2 and QStroke are only valid for estimating risk of primary CVD events; subsequent CVD events were modelled based on individual age, sex and prior CVD event only. Calibration was carried out to ensure that the total annual event rate for MI and stroke matched current data from Hospital Episode Statistics. ${ }^{31}$ In addition to CVD, individuals in the model also have an annual risk of developing microvascular complications of diabetes, major bleeding, osteoarthritis, depression, breast and bowel cancer, dementia, and of dying. Each health state is associated with healthcare costs (with stroke, osteoarthritis and dementia also associated with social care costs), and a health-related quality of life decrement (online supplementary file 1 ). Model outcomes include costs in 2017/18 UK pounds, life years, quality adjusted life years (QALYs), costeffectiveness (measured through net monetary benefit (NMB), assuming a value of $£ 20000$ per QALY) and CVD events prevented. Costs, QALYs and life years were discounted at $3.5 \%$ according to the NICE reference case.

The model includes correlation between different chronic diseases in several different ways (described fully in online supplementary file 1). First, many of the modelled conditions are represented in HSE 2014 so there is correlation between conditions from baseline. Second, the trajectories of metabolic risk factors (BMI, blood pressure, cholesterol and HbAlc) are correlated with each other and with other patient characteristics. Third, many of the risk equations used in the model to determine risk of disease for one condition have coefficients relating to one or more of the other conditions. Fourth, diagnostic criteria for each condition and the probability that individuals undergo diagnostic tests vary depending on whether or not another underlying condition is present. No good evidence about differential treatment effects in people with additional comorbid conditions or undergoing multiple treatment interventions could be identified, so potential correlations between treatments were not included; this is a limitation of the model.

\section{Model analyses}

To compare current care levels of detection and management in England with improved levels of detection and management it was essential to obtain good quality information about the proportions of people currently diagnosed with each high risk condition and well managed using each intervention included in the model (summarised in table 1). Estimates of the total numbers of people currently suffering from each high risk condition were obtained from National Cardiovascular Intelligence Network (NCVIN) prevalence models (available for $\mathrm{AF}$, diabetes, hypertension and $\mathrm{CKD}),{ }^{32-35}$ and data within the HSE 2014, ${ }^{19}$ while diagnosed prevalence was obtained primarily from the Quality and Outcomes
Framework (QOF) 2016/17. ${ }^{36}$ The percentage currently diagnosed with each high risk condition was calculated by dividing the diagnosed prevalence by the total estimated prevalence. Current care management was estimated separately for each modelled intervention that a high risk group was eligible for (see table 1 and online supplementary file 1 ), and was defined as the number currently undergoing each intervention divided by the number eligible for that intervention. A variety of data sources were used, including QOF, ${ }^{36}$ the National Diabetes Audit, ${ }^{37}$ the NHS DPP pilot study, ${ }^{38}$ NHS Digital: NHS Stop smoking services, ${ }^{39}$ and published data found through searches (see online supplementary file 1 for details).

Two analyses were carried out. In the first analysis, current care levels of detection and management with each intervention were compared against a scenario of $100 \%$ diagnosis of all high risk conditions, assuming either current levels of management or management of all diagnosed, eligible individuals with each intervention according to NICE guidelines, to obtain an estimate of the total benefits that could be accrued through maximising detection. This was achieved by assuming that all individuals with a high risk condition at baseline were diagnosed in the first modelled year, and that anyone developing a high risk condition in subsequent years would be diagnosed within the year of developing the condition. It was assumed that current levels of NHS Health Check and annual review were operating and that all additional diagnoses occurred through unspecified opportunistic detection mechanisms, for which the cost of diagnosis in individuals with high risk conditions was included, but the (unknown) cost of detecting the additional cases was not. Under the scenario of $100 \%$ detection and NICE guideline management, it was additionally assumed that all individuals would undergo all interventions for which they were eligible according to NICE guidelines, with $100 \%$ uptake and $0 \%$ discontinuation.

In the second analysis, each high risk group was analysed separately to investigate the proportional share of benefits obtained by each group through optimising detection and management. To achieve this objective, the detection of each high risk condition in turn was set to $100 \%$, again assuming either current levels of management with each intervention or NICE guideline management of the high risk condition. Detection strategies were compared in terms of total benefits to the NHS, assessed at 5, 10 and 25 year time horizons. At 25 years the youngest individuals in the model are aged 40 and becoming eligible for NHS Health Checks, so it was not thought suitable to project model outcomes beyond this point.

For both analyses, probabilistic sensitivity analysis (PSA) was carried out using 2000 model runs to account for model non-linearity and to provide an estimate of uncertainty around the results.

Patient and public involvement

Patients and the public were not involved in this study. 
Table 1 Summary of definitions, data and data sources used relating to diagnosis and management of the six CVD high risk conditions

\begin{tabular}{|c|c|c|c|c|c|}
\hline \multicolumn{3}{|c|}{ CVD high risk conditions } & \multicolumn{2}{|l|}{ Diagnosis } & \multirow{2}{*}{$\begin{array}{l}\text { Management } \\
\text { CVD risk management interventions } \ddagger\end{array}$} \\
\hline Condition & Definition in analysis & $\begin{array}{l}\text { Total } \\
\text { estimated } \\
\text { prevalence* }\end{array}$ & $\begin{array}{l}\text { Current } \\
\text { diagnosed } \\
\text { prevalence* }\end{array}$ & $\begin{array}{l}\text { Proportion } \\
\text { currently } \\
\text { diagnosed } \dagger\end{array}$ & \\
\hline $\begin{array}{l}\text { High } \\
\text { cholesterol/ } \\
\text { QRISK } \geq 10 \%\end{array}$ & $\begin{array}{l}\text { 10year QRISK2 score } \\
\geq 10 \% \text { or familial } \\
\text { hypercholesterolaemia }\end{array}$ & $34 \%^{19}$ & $\begin{array}{l}\text { No data } \\
\text { found }\end{array}$ & $11 \% \S^{9}$ & $\begin{array}{l}\text { Lipid modification therapy; } \\
\text { antihypertensives; anticoagulants; weight } \\
\text { management; smoking cessation; blood } \\
\text { pressure self-monitoring; medicines use } \\
\text { review }\end{array}$ \\
\hline Hypertension & $\begin{array}{l}\mathrm{BP} \geq 140 / 90 \text { or } 140 / 80 \\
\text { with diabetes or } 130 / 80 \\
\text { with diabetes and } \\
\text { chronic kidney disease or } \\
\text { microvascular disease }\end{array}$ & $28 \%^{34}$ & $17 \%{ }^{36}$ & $60 \%$ & $\begin{array}{l}\text { Antihypertensives; weight management; } \\
\text { smoking cessation; blood pressure self- } \\
\text { monitoring; medicines use review }\end{array}$ \\
\hline Atrial fibrillation & Atrial fibrillation & $3 \%^{35}$ & $2.3 \%{ }^{36}$ & $76 \%$ & $\begin{array}{l}\text { Anticoagulants; weight management; } \\
\text { smoking cessation; medicines use review }\end{array}$ \\
\hline \multirow[t]{3}{*}{ Diabetes } & Type 1 diabetes & $0.6 \%{ }^{19}$ & $0.6 \%$ & $100 \% \rrbracket$ & \multirow{3}{*}{$\begin{array}{l}\text { Lipid modification therapy; } \\
\text { antihypertensives; blood glucose lowering } \\
\text { medication; structured diabetes education; } \\
\text { weight management; smoking cessation; } \\
\text { insulin pump; blood pressure self } \\
\text { monitoring; medicines use review }\end{array}$} \\
\hline & Type 2 diabetes & $7.8 \%^{32}$ & $6.0 \%{ }^{36}$ & $78 \%$ & \\
\hline & Combined & $8.4 \%$ & $6.6 \%$ & $78 \%$ & \\
\hline $\begin{array}{l}\text { Non-diabetic } \\
\text { hyperglycaemia }\end{array}$ & $\begin{array}{l}\mathrm{HbA} 1 \mathrm{c} 6 \%-6.5 \%(42- \\
48 \mathrm{mmol} / \mathrm{mol})\end{array}$ & $11 \%{ }^{19}$ & $1.2 \%^{32}$ & $11 \%$ & $\begin{array}{l}\text { Diabetes prevention programme; weight } \\
\text { management; smoking cessation }\end{array}$ \\
\hline $\begin{array}{l}\text { Chronic kidney } \\
\text { disease }\end{array}$ & $\begin{array}{l}\text { Chronic kidney disease } \\
\text { stage } 3 a \text { and above }\end{array}$ & $6 \%^{33}$ & $4 \%^{36}$ & $65 \%$ & $\begin{array}{l}\text { Antihypertensives; weight management; } \\
\text { individualised nutritional advice; smoking } \\
\text { cessation; blood pressure self monitoring; } \\
\text { medicines use review }\end{array}$ \\
\hline
\end{tabular}

${ }^{*}$ Prevalence in England for individuals aged 16 and over.

†Calculated as diagnosed prevalence/total estimated prevalence.

‡Note that some of these have additional eligibility criteria, for example, only smokers eligible for smoking cessation; only overweight/obese eligible for weight management; blood pressure criteria for antihypertensives etc.

§Of patients with a recorded QRISK score. Assumes that recording of QRISK score is independent of value.

ๆAssumed that all individuals with type 1 diabetes are diagnosed.

CVD, cardiovascular disease.

\section{RESULTS}

\section{Detection of all high risk individuals}

Model results indicate that detection of all high risk individuals followed by current levels of management could save £68billion for the NHS and social care, prevent 3.4 million CVD events, and gain 4.9 million QALYs over the next 25 years compared with current care (table 2 and figure 1). The intervention is expected to be cost saving (NHS and PSS savings outweigh intervention costs) within 10 years. Alternatively, if all individuals are also managed according to NICE guidelines the health benefits increase considerably at all time points, with 5.2 million CVD events avoided and 8.1 million QALYs gained by 25 years. Cost savings are slightly lower at 25 years ( $£ 61$ billion) and the intervention is not expected to be cost saving until year 13; this is due to substantially higher intervention costs not entirely offset by greater NHS and PSS savings. Distribution of PSA samples on the cost-effectiveness plane for the 25 year horizon shows that the vast majority of points for both detection scenarios are located in the south-eastern quadrant, indicating a high probability of being cost saving (supplementary file 2).

Detection of $100 \%$ of high risk individuals is projected to lead to increases in the cost of all modelled management interventions (online supplementary file 2), with the highest costs arising due to treatment of previously undiagnosed type 2 diabetes and usage of anticoagulants in people previously undiagnosed with AF. The model also predicts a reduction in costs of NHS Health Check, which is due to fewer people meeting eligibility criteria because the analysis assumes that the additional detection is happening through unspecified opportunistic methods and not through the NHS Health Check itself.

Most of the NHS and PSS cost savings come from prevention of CVD and microvascular complications of diabetes (including ulcer, amputation and retinopathy); however, the model predicts small net increases (relative to CVD savings) in the costs of end stage renal failure, osteoarthritis, breast and bowel cancer, depression, dementia and major bleed over the lifetime horizon 
Table 2 Incremental costs, savings and benefits accrued through $100 \%$ detection of high risk conditions compared with current detection rates. $95 \%$ credible intervals obtained through probabilistic sensitivity analysis are shown in brackets

\begin{tabular}{|c|c|c|c|c|c|c|}
\hline & \multicolumn{2}{|l|}{ 5year horizon } & \multicolumn{2}{|l|}{ 10year horizon } & \multicolumn{2}{|l|}{25 year horizon } \\
\hline & $\begin{array}{l}\text { Current care } \\
\text { management }\end{array}$ & $\begin{array}{l}\text { NICE guidelines } \\
\text { management }\end{array}$ & $\begin{array}{l}\text { Current care } \\
\text { management }\end{array}$ & $\begin{array}{l}\text { NICE guidelines } \\
\text { management }\end{array}$ & $\begin{array}{l}\text { Current care } \\
\text { management }\end{array}$ & $\begin{array}{l}\text { NICE guidelines } \\
\text { management }\end{array}$ \\
\hline Net total costs & $\begin{array}{l}£ 2.4 b \\
(-£ 3.4 b \text { to } £ 6.0 \\
\text { b) }\end{array}$ & $\begin{array}{l}£ 7.3 b \\
(-£ 6.3 b \text { to } \\
£ 15.3 b)\end{array}$ & $\begin{array}{l}-£ 1.0 \mathrm{~b} \\
(-£ 14.9 \mathrm{~b} \text { to } \\
£ 7.2 \mathrm{~b})\end{array}$ & $\begin{array}{l}£ 5.0 b \\
(-£ 23.2 b \text { to } \\
£ 22.5 b)\end{array}$ & $\begin{array}{l}-£ 67.9 b \\
(-£ 113 b \text { to } \\
-£ 32.4 b)\end{array}$ & $\begin{array}{l}-£ 61.2 b \\
(-£ 137 b \text { to } \\
-£ 10 b)\end{array}$ \\
\hline $\begin{array}{l}\text { Intervention } \\
\text { costs }\end{array}$ & $\begin{array}{l}£ 7.4 b \\
\text { (£5.7b to } £ 11.3 b)\end{array}$ & $\begin{array}{l}£ 20.9 b \\
(£ 17.3 b \text { to } \\
£ 29.3 b)\end{array}$ & $\begin{array}{l}£ 13.2 b \\
(£ 9.8 b \text { to £20.1b) }\end{array}$ & $\begin{array}{l}£ 37.1 b \\
(£ 29.7 b \text { to } \\
£ 52.3 b)\end{array}$ & $\begin{array}{l}£ 24.9 b \\
\text { (£15.9b to } \\
£ 38.8 b)\end{array}$ & $\begin{array}{l}£ 74.4 \mathrm{~b} \\
\text { (£56.2b to } \\
£ 104.7 \mathrm{~b})\end{array}$ \\
\hline $\begin{array}{l}\text { Other NHS } \\
\text { and PSS costs }\end{array}$ & $\begin{array}{l}-£ 5.0 b \\
(-£ 12.7 b \text { to } \\
-£ 1.1 b)\end{array}$ & 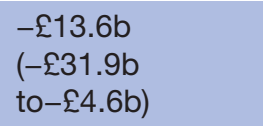 & $\begin{array}{l}-£ 14.2 \mathrm{~b} \\
(-£ 31.9 \mathrm{~b} \text { to } \\
-£ 4.8 \mathrm{~b})\end{array}$ & $\begin{array}{l}-£ 32.1 b \\
(-£ 69.3 b \text { to } \\
-£ 11.7 b)\end{array}$ & $\begin{array}{l}-£ 92.8 b \\
(-£ 145 b \text { to } \\
-£ 56 b)\end{array}$ & $\begin{array}{l}-£ 135.6 b \\
(-£ 226 b \text { to } \\
-£ 77 b)\end{array}$ \\
\hline $\begin{array}{l}\text { Total CVD } \\
\text { cases }\end{array}$ & $\begin{array}{l}-371000 \\
(-660000 \text { to } \\
-174000)\end{array}$ & $\begin{array}{l}-891000 \\
(-1.56 m \text { to } \\
-0.43 m)\end{array}$ & $\begin{array}{l}-879000 \\
(-1.3 m \text { to } \\
-533000)\end{array}$ & $\begin{array}{l}-1.72 m \\
(-2.67 m \text { to } \\
-1.03 m)\end{array}$ & $\begin{array}{l}-3.36 m \\
(-4.20 m \text { to } \\
-2.53 m)\end{array}$ & $\begin{array}{l}-5.23 m \\
(-6.64 m \text { to } \\
-3.98 m)\end{array}$ \\
\hline of which MI & $\begin{array}{l}-81000 \\
(-195000 \text { to } \\
-8000)\end{array}$ & $\begin{array}{l}-189000 \\
(-429000 \text { to }-36 \\
000)\end{array}$ & $\begin{array}{l}-203000 \\
(-399000 \text { to } \\
-53000)\end{array}$ & $\begin{array}{l}-402000 \\
(-804000 \text { to } \\
-116000)\end{array}$ & $\begin{array}{l}-837000 \\
(-1.39 m \text { to } \\
-0.37 m)\end{array}$ & $\begin{array}{l}-1.36 m \\
(-2.24 m \text { to } \\
-0.60 m)\end{array}$ \\
\hline $\begin{array}{l}\text { of which } \\
\text { stroke }\end{array}$ & $\begin{array}{l}-123000 \\
(-337000 \text { to } \\
-16000)\end{array}$ & $\begin{array}{l}-301000 \\
(-779000 \text { to } \\
-63000)\end{array}$ & $\begin{array}{l}-299000 \\
(-684000 \text { to } \\
67000)\end{array}$ & $\begin{array}{l}-608000 \\
(-1.41 \mathrm{~m} \text { to } \\
-0.16 \mathrm{~m})\end{array}$ & $\begin{array}{l}-1.28 m \\
(-2.28 m \text { to } \\
-0.41 m)\end{array}$ & $\begin{array}{l}-2.01 m \\
(-3.71 m \text { to } \\
-0.69 m)\end{array}$ \\
\hline Life years & $\begin{array}{l}95000 \\
(5000 \text { to } 233000)\end{array}$ & $\begin{array}{l}264000 \\
(73000 \text { to } \\
598000)\end{array}$ & $\begin{array}{l}473000 \\
(141000 \text { to } \\
953000)\end{array}$ & $\begin{array}{l}1.12 m \\
(0.44 m \text { to } 2.20 m)\end{array}$ & $\begin{array}{l}3.28 \mathrm{~m} \\
(2.08 \mathrm{~m} \text { to } 4.83 \mathrm{~m})\end{array}$ & $\begin{array}{l}5.68 \mathrm{~m} \\
\text { (3.33m to } 9.00 \mathrm{~m})\end{array}$ \\
\hline QALYs & $\begin{array}{l}187000 \\
(45000 \text { to } \\
416000)\end{array}$ & $\begin{array}{l}540000 \\
(206000 \text { to } \\
1.13 \mathrm{~m})\end{array}$ & $\begin{array}{l}747000 \\
(302000 \text { to } \\
1.40 \mathrm{~m})\end{array}$ & $\begin{array}{l}1.79 \mathrm{~m} \\
(0.79 \mathrm{~m} \text { to } 3.40 \mathrm{~m})\end{array}$ & $\begin{array}{l}4.93 \mathrm{~m} \\
(3.38 \mathrm{~m} \text { to } 6.86 \mathrm{~m})\end{array}$ & $\begin{array}{l}8.10 \mathrm{~m} \\
(5.04 \mathrm{~m} \text { to } \\
12.19 \mathrm{~m})\end{array}$ \\
\hline $\begin{array}{l}\text { Net monetary } \\
\text { benefit }\end{array}$ & $\begin{array}{l}£ 1.3 b \\
(-£ 4.3 b \text { to } \\
£ 10.5 b)\end{array}$ & $\begin{array}{l}£ 3.5 b \\
(-£ 9.4 b \text { to } \\
£ 27.4 b)\end{array}$ & $\begin{array}{l}£ 15.9 b \\
\text { (£0.7b to £40.9b) }\end{array}$ & $\begin{array}{l}£ 30.8 b \\
(-£ 3.6 b \text { to } \\
£ 87.1 b)\end{array}$ & $\begin{array}{l}£ 166 b \\
\text { (£107b to £242b) }\end{array}$ & $\begin{array}{l}£ 223 b \\
\text { (£123b to £366b) }\end{array}$ \\
\hline
\end{tabular}

CVD, cardiovascular disease; MI, myocardial infarction; NICE, National Institute for Health and Care Excellence; QALY, quality adjusted life year.

(online supplementary file 2). This is likely to be due to several reasons: (1) CVD prevention reduces mortality, meaning that people live for longer and so are more likely to succumb to other conditions, particularly those with a big age component such as cancer, dementia and end stage renal failure; (2) being given a diagnosis of diabetes is linked to higher rates of depression in the model, so increasing detection of diabetes will increase depression costs; (3) anticoagulant usage is potentially associated with a small increased risk of major bleed, so diagnosing more people with AF may result in a higher prevalence of major bleed.

\section{Determining who benefits from maximal detection}

The results indicate that different high risk groups are likely to benefit most from maximising detection in the short term $(<10$ years $)$ compared with the long term ( $>10$ years). In the short term, maximising detection of individuals with high cholesterol/QRISK2 of at least $10 \%$ accrues the greatest cost savings and QALY gains and prevents the most CVD cases (table 3 and figure 2).
This is likely to occur due to the high population prevalence of people with QRISK2 of at least 10\%, of which the proportion thought to be currently detected is fairly low (see table 1), and the high risk of CVD events in the near future that these individuals have. At five years, detection of most of the high risk groups (with the exception of high cholesterol/QRISK2 $\geq 10 \%$ and CKD) is projected to cost money overall as insufficient benefits have accrued to overcome the initial costs of additional diagnosis and management. However, the balance changes over time, with cost -savings outweighing intervention costs for the diabetes and hypertension subgroups by around 10-15 years (online supplementary file 2 ). Note that with the exception of diabetes detection at year 25 there is high uncertainty around whether or not detection of individual conditions will be cost saving (table 3 and online supplementary file 2).

In the long term maximising detection of diabetes is the most beneficial strategy, which is likely to reflect the long term complications associated with the condition and the 


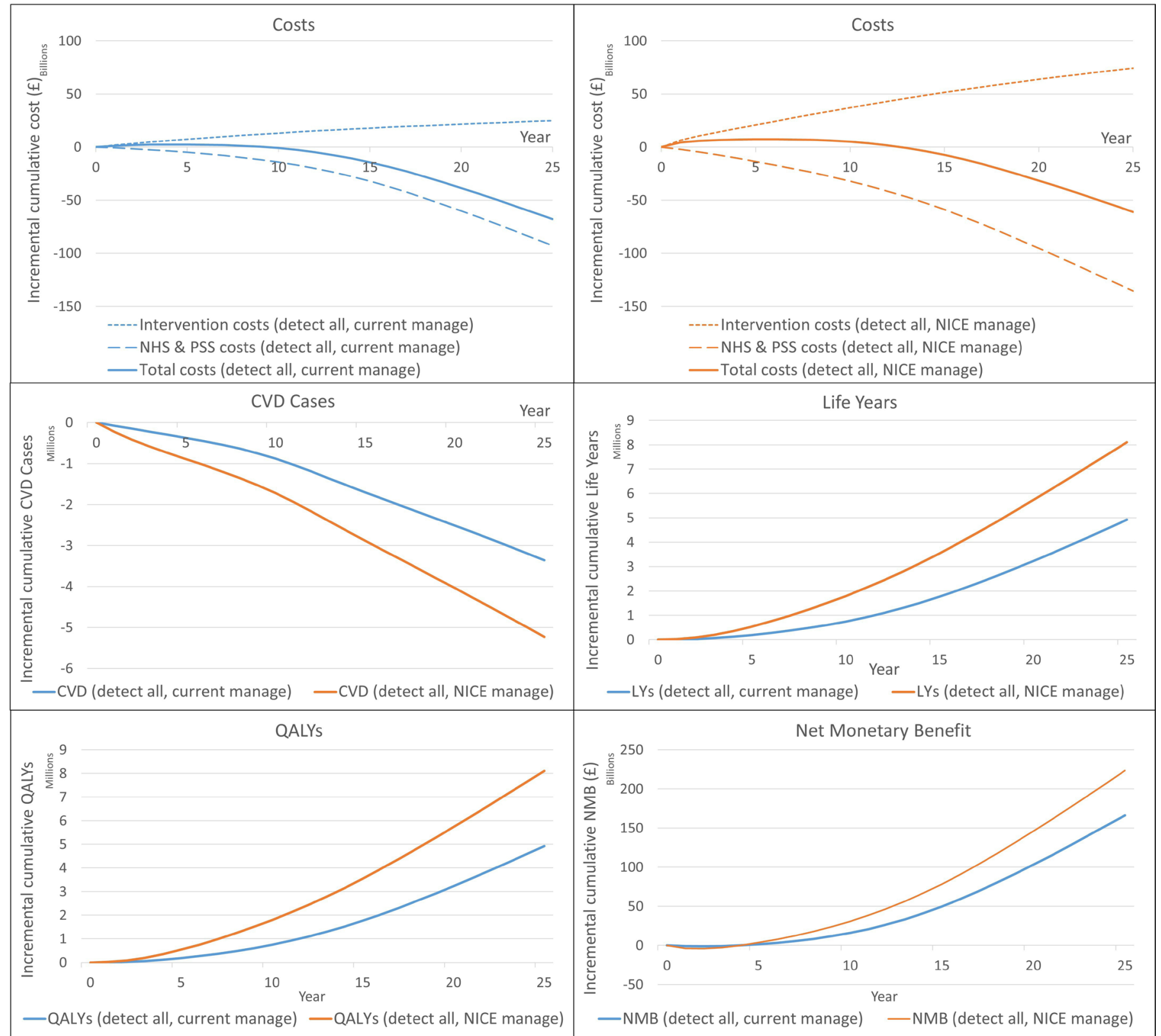

Figure 1 Trajectories showing the accumulation of incremental costs, savings and health benefits over the 25 year horizon under two scenarios for $100 \%$ detection of all high risk conditions: current levels of management (blue) or NICE guideline levels of management (orange). CVD, cardiovascular disease; LY, life years; NICE, National Institute for Health and Care Excellence; NMB, net monetary benefit; QALY, quality adjusted life year.

benefits of early diagnosis. The total benefits that accrue to the NHS through maximising detection of $\mathrm{AF}$ and CKD are relatively small despite the very high risk of CVD that these conditions confer due to the low prevalence of these conditions in the population (see table 1). Maximising detection of AF is also the most costly strategy at 25 years, likely to be due to the relatively high cost of anticoagulant treatment compared with most other interventions in the model. Note that the total benefits when all high risk groups are detected simultaneously is not identical to the sum of all benefits when each high risk group is detected individually due to some individuals having multiple comorbid high risk conditions and so benefiting to a greater extent from multiple detection in the former analysis, and counted twice in the latter analysis.

For all conditions, management according to NICE guidelines produces greater health benefits than current management, but also tends to be more costly. Interestingly, for diabetes, managing all patients according to NICE guidelines is only slightly more beneficial than current management (figure 2). This is mainly due to the relatively good adherence to NICE guidelines for people with diabetes in current practice, promoted through QOF and the national diabetes audit. ${ }^{36} 37$ PSA indicates that there is a high probability of cost-effectiveness within 25 years, under both 
Table 3 Net total incremental costs accrued through 100\% detection of each high risk condition separately. 95\% credible intervals obtained through probabilistic sensitivity analysis are shown in brackets

\begin{tabular}{|c|c|c|c|c|c|c|}
\hline & \multicolumn{2}{|l|}{ 5year horizon } & \multicolumn{2}{|l|}{ 10year horizon } & \multicolumn{2}{|l|}{25 year horizon } \\
\hline & $\begin{array}{l}\text { Current care } \\
\text { management }\end{array}$ & $\begin{array}{l}\text { NICE } \\
\text { guidelines }\end{array}$ & $\begin{array}{l}\text { Current care } \\
\text { management }\end{array}$ & $\begin{array}{l}\text { NICE } \\
\text { guidelines }\end{array}$ & $\begin{array}{l}\text { Current care } \\
\text { management }\end{array}$ & NICE guidelines \\
\hline Hypertension & $\begin{array}{l}£ 0.69 \mathrm{~b} \\
(-£ 0.8 \mathrm{~b} \text { to } £ 1.8 \mathrm{~b})\end{array}$ & $\begin{array}{l}£ 2.9 b \\
(-£ 1.1 b \text { to } \\
£ 5.1 b)\end{array}$ & $\begin{array}{l}-£ 0.05 b \\
(-£ 3.8 b \text { to } £ 2.2 b)\end{array}$ & $\begin{array}{l}£ 2.1 b \\
(-£ 6.5 b \text { to } \\
£ 7.4 b)\end{array}$ & $\begin{array}{l}-£ 1.9 b \\
(-£ 12.1 b \text { to } \\
£ 5.3 b)\end{array}$ & $\begin{array}{l}-£ 2.1 \mathrm{~b} \\
(-£ 22.0 \mathrm{~b} \text { to } \\
£ 10.7 \mathrm{~b})\end{array}$ \\
\hline $\begin{array}{l}\text { High cholesterol/ } \\
\text { QRISK } \geq 10 \%\end{array}$ & $\begin{array}{l}-£ 1.1 b \\
(-4.4 b \text { to } £ 0.7 b)\end{array}$ & $\begin{array}{l}-£ 1.1 b \\
(-10.4 b \text { to } \\
£ 3.2 b)\end{array}$ & $\begin{array}{l}-£ 2.3 \mathrm{~b} \\
(-£ 9.3 \mathrm{~b} \text { to } £ 1.7 \mathrm{~b})\end{array}$ & $\begin{array}{l}-£ 3.8 b \\
(-£ 21.6 b \text { to } \\
£ 5.4 b)\end{array}$ & $\begin{array}{l}-£ 2.9 b \\
(-£ 17.2 b \text { to } \\
£ 7.8 b)\end{array}$ & $\begin{array}{l}-£ 2.9 b \\
(-£ 35.6 b \text { to } \\
£ 18.4 b)\end{array}$ \\
\hline Diabetes & $\begin{array}{l}£ 0.49 \mathrm{~b} \\
(-£ 1.3 \mathrm{~b} \text { to } 22.4 \mathrm{~b})\end{array}$ & $\begin{array}{l}£ 2.6 \mathrm{~b} \\
(-£ 1.2 \mathrm{~b} \text { to } \\
£ 6.2 \mathrm{~b})\end{array}$ & $\begin{array}{l}-£ 1.2 \mathrm{~b} \\
(-£ 6.8 \mathrm{~b} \text { to } £ 3.4 \mathrm{~b})\end{array}$ & $\begin{array}{l}£ 2.4 b \\
(-£ 7.7 b \text { to } \\
£ 11.5 b)\end{array}$ & $\begin{array}{l}-£ 56.7 \mathrm{~b} \\
(-£ 92.6 \mathrm{~b} \text { to } \\
-£ 29.9 \mathrm{~b})\end{array}$ & $\begin{array}{l}-£ 49.3 b \\
(-£ 98.5 b \text { to } \\
-£ 17.3)\end{array}$ \\
\hline $\mathrm{NDH}$ & $\begin{array}{l}£ 2.2 \mathrm{~b} \\
(£ 1.1 \mathrm{~b} \text { to } £ 3.0 \mathrm{~b})\end{array}$ & $\begin{array}{l}£ 3.6 b \\
\text { (£1.9b to } £ 5.1 b)\end{array}$ & $\begin{array}{l}£ 2.1 \mathrm{~b} \\
\text { (-£0.8b to } £ 4.4 \mathrm{~b})\end{array}$ & $\begin{array}{l}£ 3.7 \mathrm{~b} \\
\text { (£0.4b to } £ 6.5 \mathrm{~b})\end{array}$ & $\begin{array}{l}£ 3.6 b \\
(-£ 7.1 b \text { to } £ 13.3 b)\end{array}$ & $\begin{array}{l}£ 4.4 b \\
(-£ 4.1 b \text { to } \\
£ 17.6 b)\end{array}$ \\
\hline $\mathrm{AF}$ & $\begin{array}{l}£ 0.39 b \\
(-£ 1.2 b \text { to } £ 2.3 b)\end{array}$ & $\begin{array}{l}£ 1.1 b \\
(-£ 1.7 b \text { to } \\
£ 5.9 b)\end{array}$ & $\begin{array}{l}£ 0.9 b \\
(-£ 1.8 b \text { to } £ 4.1 b)\end{array}$ & $\begin{array}{l}£ 2.1 b \\
(-£ 2.6 b \text { to } \\
£ 9.5 b)\end{array}$ & $\begin{array}{l}£ 2.5 b \\
(-£ 2.6 b \text { to } £ 9.8 b)\end{array}$ & $\begin{array}{l}£ 4.7 b \\
(-£ 4.1 b \text { to } £ 17.6)\end{array}$ \\
\hline CKD & $\begin{array}{l}-£ 0.32 b \\
(-£ 1.3 b \text { to } £ 0.3 b)\end{array}$ & $\begin{array}{l}-£ 1.4 b \\
(-£ 4.3 b \text { to } \\
£ 0.5 b)\end{array}$ & $\begin{array}{l}-£ 0.53 b \\
(-£ 2.4 b \text { to } £ 0.9 b)\end{array}$ & $\begin{array}{l}-£ 2.1 b \\
(-£ 6.8 b \text { to } \\
£ 1.2 b)\end{array}$ & $\begin{array}{l}-£ 0.42 \mathrm{~b} \\
(-£ 4.7 \mathrm{~b} \text { to } £ 3.4 \mathrm{~b})\end{array}$ & $\begin{array}{l}-£ 1.8 b \\
(-10.5 b \text { to } \\
£ 5.3 b)\end{array}$ \\
\hline
\end{tabular}

AF, atrial fibrillation; CKD, chronic kidney disease; NDH, non-diabetic hyperglycaemia; NICE, National Institute for Health and Care Excellence.

detection scenarios and for all high risk conditions (online supplementary file 2).

\section{DISCUSSION}

This analysis indicates that large cost savings and health benefits could accrue to the NHS if all individuals with conditions that increase CVD risk could be detected, with detection of undiagnosed diabetes cases likely to produce the greatest benefits. Ensuring that all conditions are managed according to NICE guidelines once diagnosed would further increase the health benefits without substantially increasing the costs. Note that most individual results are uncertain due to the large number of uncertain parameters in the model and the lack of information about how these are correlated; however, in most cases the balance of probabilities is in favour of additional detection and management over the long term. The benefits of detection and management for each high risk condition vary depending on a number of factors, including the proportions currently undiagnosed, the proportions currently poorly managed, the costs and effectiveness of the key management interventions, and the increased risk for CVD and other complications that each condition confers. In addition to these factors, the high cost savings and health benefits estimated over the long term for detecting people with diabetes are likely to arise due to the particular benefits of early detection of this condition. Those diagnosed at lower HbAlc levels have a better prognosis than those diagnosed at higher HbA1c levels, ${ }^{40}$ and so are less likely to progress to expensive treatments such as insulin, or develop expensive and seriously detrimental complications such as microvascular disease.

The key strength of this analysis is its basis in a single modelling framework, which includes most elements of current practice in CVD prevention in people at high risk, and thereby enables comparison of different detection and management scenarios. An assessment of some of the competing risks for mortality and morbidity is also possible due to the inclusion in the model of a range of additional conditions, including dementia, depression, some cancers and osteoarthritis. Although it is important to note that these conditions have been modelled in a less sophisticated way than cardiovascular disease, and that the model does not include all competing risks, so there may be additional long-term costs to preventing CVD not included in the model. Furthermore, the patient level structure of the model preserves correlations between high risk conditions that exist in the English population, meaning that the combined benefits of detecting multiple high risk conditions can be assessed without double counting or underestimating CVD risk in people with multiple comorbidities. However, there are also several limitations. First, the $100 \%$ detection scenario is not a realistic target and overestimates the benefits that could be reasonably achieved. PHE has produced a set of CVD ambitions which include detection of $85 \%$ of $\mathrm{AF}$ cases, $80 \%$ of hypertension cases, and to have performed a CVD risk assessment on $75 \%$ of people aged $40-74$ by $2029 .{ }^{41}$ Setting realistic detection targets for the other high risk conditions could help galvanise improvements and would 


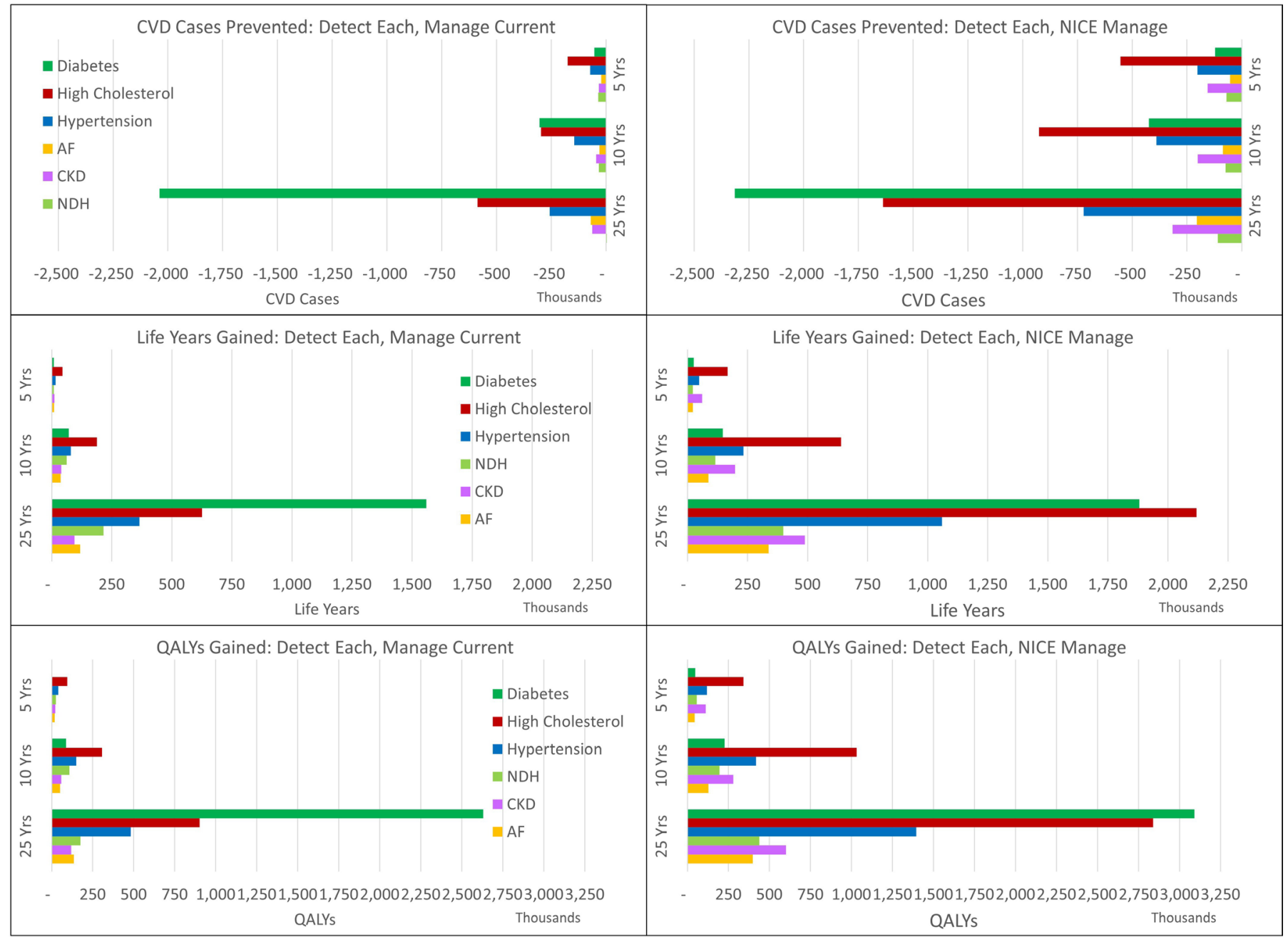

Figure 2 Accrual of health benefits in each high risk group when detection is maximised compared with current care. CVD cases prevented (top), life years gained (middle) and QALYs gained (bottom) for $100 \%$ detection of each high risk condition followed by either current levels of management (left) or NICE guideline levels of management (right). AF, atrial fibrillation; CVD, cardiovascular disease; NDH, non-diabetic hyperglycaemia; NICE, National Institute for Health and Care Excellence; QALY, quality adjusted life year.

allow an estimation of the cost savings and health benefits that could accrue. A second limitation is the ability of the model to accurately estimate current care, which will impact on the magnitude of the modelled benefits and which depends on a range of data sources that vary between highly accurate QOF data for diagnosed prevalence of most conditions and usage of some interventions (eg, anticoagulants), ${ }^{36}$ published observational studies based on a limited sample (eg, the DPP pilot study for current uptake of the NHS $\mathrm{DPP}^{38}$ ) and modelled estimates of total prevalence from NCVIN. ${ }^{32-35}$ Third, the CVD prevention benefits of improving detection and management may be underestimated because the model only includes the CVD outcomes within QRISK2, ${ }^{29}$ plus congestive heart failure (peripheral vascular disease is not included for example), it does not include any CVD benefits of lifestyle management interventions that may occur above and beyond the recorded effect on metabolic factors, and it does not model secondary CVD events in a way that enables interventions to directly impact them.
In addition, the model only includes a limited number of conditions unrelated to CVD, and some CVD management interventions, particularly lifestyle interventions, may have direct benefits that go beyond those included in the model. This is particularly true of smoking cessation for example, which will have specific benefits in reducing lung cancer and chronic obstructive pulmonary disease that have not been included in the model.

While this analysis can be used to estimate how much money could potentially be spent on interventions to improve detection and management in high risk individuals, further research is needed to determine what policy changes would be required in practice. There are many reasons why people at high risk of CVD are currently insufficiently diagnosed and managed. Insufficient diagnosis may occur partly due to individuals not being offered or taking up their NHS Health Check or annual review, or not being detected despite their attendance (for example NICE guidelines for each condition are inconsistent around which other high risk conditions should be tested 
for during the annual review). Opportunistic mechanisms of detection do exist for some conditions (eg, community blood pressure assessments, or using blood pressure monitors to detect $\mathrm{AF}$ ), but even then they are not explicitly mentioned in NICE guidelines or consistently available. Poor management may be due to clinical practice not always following NICE guidelines, but may also be owing to patients choosing not to undergo treatment, poorly adhering to treatment or discontinuing treatment. Each of these issues would require different strategies for improvement, from changing guidelines to ensure detection of all six conditions is maximised at NHS Health Check and annual review; to incentivising best practice, perhaps through developing new QOF indicators; to developing strategies to improve opportunistic detection of high risk conditions, and patient uptake and adherence to interventions. A further barrier to improvement is the short-term nature of much decision making, when improvements to health and cost savings will not be realised until far into the future. Further research is required to identify the reasons for insufficient detection and management of high risk conditions and to develop acceptable and cost-effective solutions.

In summary, this analysis has shown that improving detection and management of the six CVD high risk groups identified through the NHS RightCare pathway is likely to result in significant health benefits and cost savings. There are other population groups at particularly high risk of CVD, including people with obesity, those with learning difficulties and those with mental illness. Further health benefits and cost savings could potentially be obtained through improving CVD risk management of these individuals. Primary prevention of CVD in the general population, including preventing high risk conditions from developing in the first place, is also likely to be highly cost effective, and could be evaluated as part of future work within the same modelling framework.

Acknowledgements We would like to thank the PHE working group and the project steering group for advice throughout the project and pointers to useful data, particularly concerning current care in England. Many thanks also to Dan Pollard for advice about modelling type 1 diabetes, Suzy Paisley for advice about search strategies and Nick Payne for his input into steering group meetings. Finally, this work could not have been carried out without the SPHR Diabetes Prevention Model, which was funded by the National Institute for Health Research's School for Public Health Research.

Contributors CT was principle investigator for the project, and carried out most of the project planning, model reviews, model development, analysis of model results and writing of the manuscript. She is guarantor. $A B$ assisted in project planning, advised on model development and analyses, and revised the draft manuscript. EG carried out most of the systematic reviewing for model parameters and revised the draft manuscript. HYS contributed to conceptual modelling, advised on analyses and revised the draft manuscript. GB carried out the cost-effectiveness review, contributed to conceptual modelling and revised the draft manuscript. DB gathered and analysed data for the model, and revised the draft manuscript. HBW devised and carried out most of the searches and revised the draft manuscript. MG carried out data analysis for the model, assisted with model coding and revised the draft manuscript. JL carried out some systematic reviewing for model parameters and revised the draft manuscript. MC devised and carried out some of the searches and revised the draft manuscript. LH assisted with analysis of model results and revised the draft manuscript. KC helped devise the search strategy and revised the draft manuscript. PB contributed to conceptual modelling, and revised the draft manuscript. The corresponding author attests that all listed authors meet authorship criteria and that no others meeting the criteria have been omitted.

Funding Model development was funded originally by the National Institute for Health Research (NIHR)'s School for Public Health Research (SPHR). Model adaptation and a set of preliminary analyses were carried out as part of a project commissioned and funded by Public Health England (PHE) to develop a return on investment tool for cardiovascular disease prevention. The views expressed are those of the authors and not necessarily those of PHE or the NIHR. The model used for this analysis was developed for a Public Health England (PHE) commissioned return on investment tool. However, PHE did not have any influence over the choice of analysis for publication or the findings of the analysis. The decision to submit the article for publication was made entirely independently of the funders

Competing interests All authors have completed the ICMJE uniform disclosure form at www.icmje.org/coi_disclosure.pdf and declare that the only support for the submitted work was from the funders mentioned. The authors have no financial relationships with any organisations that might have an interest in the submitted work in the previous three years other than Public Health England and no other relationships or activities that could appear to have influenced the submitted work.

Patient consent for publication Not required.

Provenance and peer review Not commissioned; externally peer reviewed.

Data availability statement No data additional to that provided in the manuscript and supplementary files are available.

Open access This is an open access article distributed in accordance with the Creative Commons Attribution Non Commercial (CC BY-NC 4.0) license, which permits others to distribute, remix, adapt, build upon this work non-commercially, and license their derivative works on different terms, provided the original work is properly cited, appropriate credit is given, any changes made indicated, and the use is non-commercial. See: http://creativecommons.org/licenses/by-nc/4.0/.

ORCID iD

Chloe Thomas http://orcid.org/0000-0001-8704-3262

\section{REFERENCES}

1 European Heart Network. European cardiovascular disease statistics 2017, 2017. Available: http://www.ehnheart.org/cvd-statistics/cvdstatistics-2017.html [Accessed 10 Jan 2018].

2 British Heart Foundation. Cardiovascular disease statistics 2018, 2018. Available: https://www.bhf.org.uk/what-we-do/our-research/ heart-statistics/heart-statistics-publications/cardiovascular-diseasestatistics-2018 [Accessed 15 Nov 2018].

3 NHS. NHS RightCare, 2018. Available: https://www.england.nhs.uk/ rightcare/ [Accessed 12 Jan 2018].

4 Piepoli MF, Hoes AW, Agewall S, et al. 2016 European guidelines on cardiovascular disease prevention in clinical practice: The sixth joint task force of the European society of cardiology and other societies on cardiovascular disease prevention in clinical practice (constituted by representatives of 10 societies and by invited experts) developed with the special contribution of the European association for cardiovascular prevention \& rehabilitation (EACPR). Eur Heart $J$ 2016;37:2315-81.

5 Chang KC-M, Soljak M, Lee JT, et al. Coverage of a national cardiovascular risk assessment and management programme (NHS health check): retrospective database study. Prev Med 2015;78:1-8.

6 NHS Health Scotland. The impact of keep well: an evaluation of the keep well programme from 2006 to 2012. Edinburgh: NHS Health Scotland, 2014.

7 Allen and Clarke. More heart and diabetes checks evaluation. Wellington: Ministry of Health, 2016.

8 Chang KC-M, Lee JT, Vamos EP, et al. Impact of the National health service health check on cardiovascular disease risk: a difference-indifferences matching analysis. CMAJ 2016;188:E228-38.

9 Finnikin S, Ryan R, Marshall T. Statin initiations and QRISK2 scoring in UK general practice: a thin database study. Br J Gen Pract 2017;67:e881-7.

10 Crossan C, Lord J, Ryan R, et al. Cost effectiveness of case-finding strategies for primary prevention of cardiovascular disease: a modelling study. Br J Gen Pract 2017;67:e67-77.

11 Kypridemos C, Allen K, Hickey GL, et al. Cardiovascular screening to reduce the burden from cardiovascular disease: microsimulation study to quantify policy options. BMJ 2016;353:i2793.

12 Mytton OT, Jackson C, Steinacher A, et al. The current and potential health benefits of the National health service health 
check cardiovascular disease prevention programme in England: a microsimulation study. PLoS Med 2018;15:e1002517.

13 Size of the prize: reducing heart attacks and strokes, 2017. Available: https://www.healthcheck.nhs.uk/commissioners-and-providers/data/ size-of-the-prize-and-nhs-health-check-factsheet/ [Accessed 16 Jan 2018].

14 Lord J, Willis S, Eatock J, et al. Economic modelling of diagnostic and treatment pathways in National Institute for health and care excellence clinical guidelines: the modelling algorithm pathways in guidelines (MAPGuide) project. Health Technol Assess 2013;17:1-192

15 Ara R, Pandor A, Stevens J, et al. Early high-dose lipid-lowering therapy to avoid cardiac events: a systematic review and economic evaluation. Health Technol Assess 2009;13:1-118.

16 Breeze PR, Thomas C, Squires $\mathrm{H}$, et al. Cost-Effectiveness of population-based, community, workplace and individual policies for diabetes prevention in the UK. Diabet Med 2017;34:1136-44.

17 Breeze PR, Thomas C, Squires H, et al. The impact of type 2 diabetes prevention programmes based on risk-identification and lifestyle intervention intensity strategies: a cost-effectiveness analysis. Diabet Med 2017;34:632-40.

18 Thomas C, Sadler S, Breeze P, et al. Assessing the potential return on investment of the proposed UK NHS diabetes prevention programme in different population subgroups: an economic evaluation. BMJ Open 2017;7:e014953.

19 NHS Digital. Health survey for England 2014, 2014. Available: https:// data.gov.uk/dataset/health_survey_for_england

20 National Institute for Health and Care Excellence. Nice guideline CG71: familial hypercholesterolaemia: identification and management, 2008. Available: https://www.nice.org.uk/guidance/ $\operatorname{cg} 71$

21 National Institute for Health and Care Excellence. Hypertension in adults: diagnosis and management (NICE guideline CG127), 2011. Available: https://www.nice.org.uk/guidance/cg127

22 National Institute for Health and Care Excellence. Type 2 diabetes; prevention in people at high risk (NICE public health guideline PH38), 2012. Available: https://www.nice.org.uk/guidance/ph38

23 National Institute for Health and Care Excellence. Atrial fibrillation: management (NICE guideline CG180), 2014. Available: https://www. nice.org.uk/guidance/cg180

24 National Institute for Health and Care Excellence. Cardiovascular disease: risk assessment and reduction, including lipid modification (NICE guideline CG181), 2014. Available: https://www.nice.org.uk/ guidance/cg181

25 National Institute for Health and Care Excellence. Chronic kidney disease in adults: assessment and management (NICE guideline CG182), 2014. Available: https://www.nice.org.uk/guidance/cg182

26 National Institute for Health and Care Excellence. Type 1 diabetes in adults; diagnosis and management (NICE guideline NG17), 2015. Available: https://www.nice.org.uk/guidance/ng17

27 National Institute for Health and Care Excellence. Type 2 diabetes in adults; management (NICE guideline NG28), 2015. Available: https:// www.nice.org.uk/guidance/ng28

28 Hippisley-Cox J, Coupland C, Brindle P. Derivation and validation of QStroke score for predicting risk of ischaemic stroke in primary care and comparison with other risk scores: a prospective open cohort study. BMJ 2013;346:f2573.
29 Hippisley-Cox J, Coupland C, Vinogradova Y, et al. Predicting cardiovascular risk in England and Wales: prospective derivation and validation of QRISK2. BMJ 2008;336:a332:1475-82.

30 Kannel WB, D'Agostino RB, Silbershatz $\mathrm{H}$, et al. Profile for estimating risk of heart failure. Arch Intern Med 1999;159:1197-204.

31 NHS Digital. Hospital episode statistics: Hospital admitted patient care activity, 2017. Available: https://data.gov.uk/dataset/8d94e03924d8-4c5d-98e1-8f9bed9423e9/hospital-episode-statistics-hesadmitted-patient-care-provider-level-analysis\#: :text=Hospital\% 20Episodes\%20Statistics\%20(HES)\%20is, down\%20to\%20the \% 20provider\%20level. [Accessed 21 May 2018].

32 Public Health England. Diabetes prevalence model estimates for local populations, 2015. Available: https://www.gov.uk/government/ publications/diabetes-prevalence-estimates-for-local-populations [Accessed 16 Jan 2018].

33 Public Health England. Ckd prevalence estimates for local and regional populations. National cardiovascular intelligence network, 2015. Available: https://www.gov.uk/government/publications/ckdprevalence-estimates-for-local-and-regional-populations [Accessed 18 May 2018].

34 Public Health England. Hypertension prevalence estimates for local populations. National cardiovascular intelligence network, 2016. Available: https://www.gov.uk/government/publications/ hypertension-prevalence-estimates-for-local-populations [Accessed 3 Jul 2018].

35 Public Health England. Atrial fibrillation prevalence estimates for local populations. National cardiovascular intelligence network, 2017. Available: https://www.gov.uk/government/publications/atrialfibrillation-prevalence-estimates-for-local-populations [Accessed 18 May 2018].

36 NHS Digital. Quality and outcomes framework 2016/17, 2017. Available: http://content.digital.nhs.uk/qof [Accessed 16 Jan 2018].

37 National diabetes audit report 1 care processes and treatment targets 2016-17, 2017. Available: https://digital.nhs.uk/data-andinformation/publications/statistical/national-diabetes-audit/nationaldiabetes-audit-report-1-care-processes-and-treatment-targets2016-17 [Accessed 16 Jan 2018].

38 NHS Digital. National diabetes prevention programme pilot study, 2017. Available: http://www.digital.nhs.uk/catalogue/PUB30119 [Accessed 16Jan 2018].

39 NHS Digital. Statistics on NHS stop smoking services in England - April 2016 to March 2017, 2017. Available: https://digital.nhs.uk/ data-and-information/publications/statistical/statistics-on-nhsstop-smoking-services-in-england/statistics-on-nhs-stop-smokingservices-in-england-april-2017-to-december-2017 [Accessed 18 May 2018].

40 Hayes AJ, Leal J, Gray AM, et al. UKPDS outcomes model 2: a new version of a model to simulate lifetime health outcomes of patients with type 2 diabetes mellitus using data from the 30 year United Kingdom prospective diabetes study: UKPDS 82. Diabetologia 2013;56:1925-33.

41 Health matters: preventing cardiovascular disease, 2019. Available: https://www.gov.uk/government/publications/health-matterspreventing-cardiovascular-disease/health-matters-preventingcardiovascular-disease 